\title{
New-onset acute symptomatic seizure in a neurological intensive care unit
}

\author{
Jaishree T. Narayanan, J. M. K. Murthy \\ Department of Neurology, The Institute of Neurological Sciences, CARE Hospital, Exhibition Road, Nampally, Hyderabad - 500 001, \\ India
}

Objective: New-onset acute symptomatic seizures can be
the presenting feature of acute neurological diseases. The
etiological spectrum of new-onset acute symptomatic
seizures and outcome may be different in developing
countries when compared to developed countries. Aim: To
study the clinical profile of new-onset acute symptomatic
seizures as the first presenting event in patients with acute
neurological illness in a neurological intensive care unit
(NICU) in a developing country. Settings and Design:
Prospective study in a NICU in a tertiary care hospital.
Materials and Methods: Consecutive patients with acute
symptomatic new-onset seizure admitted to NICU in a
tertiary care hospital over a period of 28 months. The
etiology was determined by neuroimaging and appropriate
investigations including cerebrospinal fluid examination.

Results: Of the 3,151 admissions, 66 (2.1\%) were related to new-onset acute symptomatic seizures as the first presentation. The mean age was $49.07+20.20$ years. Tonicclonic, generalized tonic-clonic or partial seizure with or without secondary generalization were the seizure type. At presentation $52(79 \%)$ patients had single seizure, $10(15 \%)$ patients had seizure clusters and four $(6 \%)$ patients presented with status epilepticus (SE). The major etiological risk factors were central nervous system (CNS) infections (32\%), metabolic disorders (32\%) and cerebrovascular diseases (21\%). In the NICU 10 (15\%) patients had early seizure recurrence and three $(4.5 \%)$ developed SE. Of these 13 patients, in nine (69\%) patients the pathology was infection-related and the other commonality was involvement of cortical gray matter. Factors associated with seizure recurrence or SE were focal cerebral lesions involving cortical gray matter or diffuse cerebral pathology, meningoencephalitis. In 69\% of these patients the pathology was infection-related. There were only two deaths, both in patients with SE and related to the underlying etiology. Conclusion: The risk of seizure recurrence and SE after the first acute symptomatic seizure is likely to be high in patients with acute focal cerebral lesions and diffuse CNS infections. The commonality in both the pathologies is cortical gray matter involvement.

Key words: Acute symptomatic, central nervous system infections, focal cerebral lesion, new-onset seizure, recurrence, status epilepticus

Seizures as the first presenting event can be the feature of acute medical or neurological disorders. ${ }^{[1]}$ New-onset acute symptomatic seizures account for $40 \%$ of new-onset seizures. ${ }^{[2]}$ Previous reports have addressed new-onset seizures in patients with nonneurological primary diagnosis admitted to medical and surgical intensive care units. $^{[3-6]}$ Very few studies have studied the frequency of seizures, mostly nonconvulsive seizures (NCSzs) and nonconvulsive status epilepticus (NCSE) in critically ill patients in neurological intensive care unit (NICU)..$^{[7-9]}$ However, no study has attempted to determine the clinical profile of new-onset acute symptomatic seizures as the first presenting event in patients with acute neurological illness. Seizures complicating acute neurological disorders invariably add an additional layer of complexity to patient management. Neurological intensive care unit provides more easily collectable data in this group of patients.

\section{Materials and Methods}

\section{Study setting and population}

Consecutive patients with new-onset acute symptomatic seizure as the first presenting event in patients with acute neurological illness admitted to NICU in a tertiary care hospital over a period of 28 months (January 2003 to April 2005) were the subjects of the study. Patients were either referred by a practicing physician or came by self-referral. The data were collected prospectively in structured 
proforma. In our hospital all patients with acute seizures are attended by the neurology team and managed initially in the NICU. In our hospital all cases of traumatic brain injury are cared by the Neurosurgery team. We practice antiepileptic drug prophylaxis in patients with traumatic brain injury.

\section{Definitions}

Acute symptomatic seizure(s) was defined as seizure(s) caused or provoked by an acute medical or neurological insult. ${ }^{[1]}$ Acute symptomatic seizures were further grouped into two broad categories: 1) acute symptomatic seizure(s) caused by acute neurological insult; and 2) acute symptomatic seizure(s) caused by acute metabolic disorder. Seizure type was classified using the classification proposed by the International League Against Epilepsy (ILAE). ${ }^{[10]}$ Seizure cluster was defined as a repetitive series or a cluster of seizures that occur within a short time but that do not meet the criteria for a diagnosis of status. ${ }^{[11]}$ Convulsive status epilepticus (SE) was defined as "(1) continuous convulsive seizure activity for more than 10 minutes or (2) two or more convulsive seizures, without full recovery of consciousness between seizures". ${ }^{[12]}$ When the initial presenting feature was seizure cluster or SE, they were considered as a single seizure while considering recurrences.

\section{Clinical data}

Data collected included details of demography, modes of presentation, seizure semiology, etiological risk factors, management and outcome. All the patients had received brain imaging (CT/MRI), interictal EEG, routine laboratory investigations including metabolic profile, toxic screening, and other appropriate investigations like lumbar puncture were done in select patients to establish the underlying etiology. Diagnosis of neurocysticercosis was based on the criteria proposed by Delbrutto et $\mathrm{al}^{[13]}$ and the diagnosis of tuberculoma was based on morphological features on contrast CT scan and or MRI. ${ }^{[14,15]}$

\section{Treatment and outcome}

The details of the antiepileptic drugs (AEDs) received, complications related to drug therapy were recorded. The outcome measures included immediate mortality and functional outcome at 30 days.

\section{Results}

Of the 3,151 admissions during the study period, 77 (2.4\%) presented with new-onset seizures and $66(2.1 \%)$ of them were related to acute, medical or neurological insult. In the remaining 11 patients, the cause of seizure was cryptogenic.

The mean age of patients with acute symptomatic seizures was $49.07+20.29$ years (six months to 80 years). Twenty-four (36\%) were aged 60 years and above, generalized tonic-clonic seizure was the seizure type in 36 (55\%) patients and in the remaining 30 (45\%) patients, the seizure type was partial with or without secondary generalization. Of the 30 patients with partial seizures, 28 (93\%) had complex partial seizure and two (7\%) had epilepsia partialis continua. At presentation 52 (79\%) patients presented with single seizure, $10(15 \%)$ patients had seizure clusters and four (6\%) patients presented with SE. Postictal Todd's palsy was noted in four (6\%) patients [Table 1].

The underlying etiological risk factors were central nervous system (CNS) infections in 21 (32\%) patients, metabolic disorders in 21 (32\%), cerebrovascular diseases (ischemic, venous and hemorrhagic) in 14 (21\%) and others in 10 (15\%). The distribution of the pathology in patients with CNS infections was meningoencephalitis in nine (43\%) and parenchymal granuloma in $12(57 \%)$ patients [(degenerative phase solitary cystic granuloma (SCG) in nine (75\%) and tuberculoma in three (25\%)] [Table 2].

The electroencephalography (EEG) was mostly interictal, done within $24 \mathrm{~h}$ after the seizure had been aborted. It was abnormal in 37 (56\%) patients, mostly nonspecific, either diffuse symmetric or focal theta or delta activity. None of the EEG showed spike or sharp wave activity and periodic discharges. There were no specific EEG features that could predict the recurrence seizures and SE.

Of the 66 patients with seizures, $10(15 \%)$ patients had early seizure recurrence and three (4.5\%) developed SE

Table 1: Etiology and presenting seizure type, seizure recurrence and status epilepticus

\begin{tabular}{|c|c|c|c|c|c|}
\hline \multirow[t]{2}{*}{ Etiological risk factor } & \multicolumn{3}{|c|}{$\begin{array}{c}\text { Seizure frequency at } \\
\text { presentation (\%) }\end{array}$} & \multicolumn{2}{|c|}{$\begin{array}{c}\text { Seizure recurrence in } \\
\text { NICU (\%) }\end{array}$} \\
\hline & Single & SC & SE & Recurrence & *SE \\
\hline Hyponatremia (15) & $15(100)$ & - & - & - & \\
\hline Stroke (14) & $11(79)$ & $3(21)$ & - & $1(7)$ & $1(7)$ \\
\hline \multicolumn{6}{|l|}{ Granulomatous lesions } \\
\hline Solitary cysticercus granuloma (9) & $5(56)$ & $4(44)$ & - & $4(44)$ & - \\
\hline Tuberculoma (3) & $2(67)$ & $1(33)$ & - & - & \\
\hline Meningoencephalitis (9) & $6(67)$ & - & $3(33)$ & $4(44)$ & $1(11)$ \\
\hline Glycemic disorders (6) & $4(67)$ & $2(33)$ & - & - & \\
\hline Others (10) & $9(90)$ & - & $1(10)$ & $1(10)$ & $1(10)$ \\
\hline
\end{tabular}

SC: Seizure cluster, SE: Status epilepticus, *All these patients presented with single seizure at admission 
Table 2: Etiological risk factors

\begin{tabular}{|c|c|c|}
\hline \multirow{2}{*}{\multicolumn{2}{|c|}{$\begin{array}{l}\text { Etiological risk factor } \\
\text { Central nervous system Infections }\end{array}$}} & \multirow{5}{*}{$\begin{array}{c}\text { Number of patients (\%) } \\
21(32)\end{array}$} \\
\hline & & \\
\hline Meningoencephalitis & 9 & \\
\hline Neurocysticercosis-SCG & 9 & \\
\hline Tuberculoma & 3 & \\
\hline Cererbrovascular diseases & & $14(21)$ \\
\hline Intracerebral hematoma & 9 & \\
\hline Ischemic & 3 & \\
\hline Cortical sino-venous thron & & \\
\hline Metabolic & & $21(32)$ \\
\hline Hypoglycemia & 2 & \\
\hline Hyperglycemia & 4 & \\
\hline Hyponatremia & 15 & \\
\hline Others & & $10(15)$ \\
\hline Alcohol & 6 & \\
\hline Hypoxic encephalopathy & 2 & \\
\hline Tumor & 1 & \\
\hline Acute disseminated & 1 & \\
\hline
\end{tabular}

SCG: Solitary cysticercus granuloma.

in the NICU. The pathology in 10 patients with seizure recurrence was focal cerebral lesions in six (60\%) (ischemic stroke one, SCG four, glioma one) and meningoencephalitis in four (40\%). The pathology in the three patients with SE was focal cerebral lesions in two (cerebral sino-venous thrombosis, CSVT) and meningoencephalitis in one patient. Of the 13 patients who had seizure recurrence or who developed SE, in nine (69\%) the pathology was infection-related.

Of the 28 patients with focal lesions, eight presented with seizure clusters (28.6\%), six (21.4\%) had early seizure recurrence and two (7\%) developed SE in the NICU. The location of focal cerebral lesions was either cortical or at the gray-white matter junction. Of the 11 patients with diffuse cerebral pathology (meningoencephalitis nine, hypoxic encephalopathy two), four (36\%) presented with SE, one (9\%) developed SE in the NICU and four (36\%) had seizure recurrence [Table 3].

The pathology in the seven patients with SE included focal cerebral lesions in two [cerebral sino-venous thrombosis (CSVT) one, acute disseminated encephalomyelitis (ADM) one)] and diffuse cerebral pathology in five (meningoencephalitis four, hypoxic encephalopathy one).

\section{Drug response}

All patients received intravenous benzodiazepines (lorazepam or midazolam) at arrival. Patients with seizure cluster and those who had seizure recurrence in the NICU received phenytoin- or sodium valproate loading dose followed by oral maintenance dose. At the time of discharge only patients who had recurrent seizures, seizure cluster and SE were kept on AEDs, either phenytoin or sodium valproate. In patients with SCG and tuberculoma AEDs were withdrawn only when the followup CT demonstrated complete resolution of the lesion. In the other patients AEDs were withdrawn at three to six months intervals. None of the patients with acute symptomatic new-onset seizures due to metabolic disorders received AED prophylaxis. None had seizure recurrence during the follow-up.

Of the seven patients who presented with SE or developed SE in the NICU, in five patients SE responded to intravenous midazolam or lorazepam followed by phenytoin- or fosphenytoin-loading dose. Both the patients who were given third drug, intravenous midazolam infusion, died. The death was related to the underlying etiological risk factors, tuberculous meningitis and CSVT.

\section{Discussion}

Seizures may herald or complicate acute neurological and medical disorders. In our study $2.1 \%$ of admissions were related to new-onset seizures occurring with acute neurological disorders. As mentioned in the methodology, all acute seizures are admitted directly from the emergency department to NICU and triaged. A retrospective study from Mayo Clinic $^{[4]}$ reported new-onset seizures in $0.8 \%$ of patients admitted to medical and surgical ICUs. A review by Bleck et $a I^{[3]}$ noted that $3.5 \%$ of patients with critical medical illness had new-onset seizures. Both these studies are incidence studies of new-onset seizures in patients with non-neurological primary diagnosis admitted to medical and surgical ICUs. Our study differs substantially from these two studies. We studied newonset seizures as the first manifestation in patients with acute neurological primary diagnosis and not incidence cases in NICU. New-onset seizures in the elderly requiring hospitalization mostly occur with acute neurological insults. ${ }^{[16-18]}$ In a retrospective study, acute symptomatic neurological insults accounted for $41 \%$ of etiologies. ${ }^{[17]}$

New-onset acute symptomatic seizures can occur as single events, brief clusters or status epilepticus. ${ }^{[3,4,19]}$ Of

Table 3: The pathology and seizure recurrence

\section{Pathology}

Focal pathology - 28*

Diffuse cerebral pathology - 11

\section{Seizure recurrence}

Seizure cluster at presentation - 9 (28.6\%)

Seizure recurrence in NICU - $5(21.4 \%)$

Status epilepticus in NICU - 2 (7\%)

Status epilepticus at presentation - $4(36 \%)$

Status epilepticus in NICU - 1 (9\%)

Seizure recurrence - 4 (36\%)
$16(57 \%)$

$9(81 \%)$

*The location of focal pathology was either cortical or gray-white matter junction, NICU - Neurological intensive care unit 
the 66 patients, cluster of seizures was the presenting event in 10 (15\%) patients. Eight patients had focal lesion on CT scan involving cortical gray matter or gray-white junction. Six of the lesions were granulomas. Seizure clusters have been reported more frequently in patients with SCG. ${ }^{[20]}$

There are scanty data regarding SE incidence in the ICU. In this series seven (11\%) patients had SE. Four patients presented with SE and three (4.5\%), incidence cases developed after admission to NICU. Bleck et $a I^{[3]}$ prospectively evaluated 1850 patients admitted to a medical ICU, four patients were admitted with primary refractory SE. Of 217 patients with nonneurological admissions who developed neurological complications, $61(28.1 \%)$ had seizures, six of these patients were in SE. Thus ten $(0.5 \%)$ of medical ICU admissions were primary or secondary SE. In the Mayo Clinic series, ${ }^{[4]}$ of the 55 patients with new-onset seizures among 27,273 patients admitted to the medical and surgical ICU, only four (7.3\%) patients developed SE.

The etiological spectrum in the present study was distinctly different when compared to the data from developed countries. ${ }^{[21,22]}$ In our study CNS infections accounted for $32 \%$ of the etiology. Similar were the observations in the other studies from developing countries. ${ }^{[19,23]}$ Solitary cystic granuloma, degenerative phase of NCC accounted for $43 \%$ of the CNS infections. In developing countries endemic to NCC, cysts in the degenerative phase is the most common cause of newonset acute symptomatic seizures. ${ }^{[24]}$

New-onset acute symptomatic seizures are different from unprovoked seizures in that they generally do not recur and usually do not need long-term AED therapy. However, this study suggests that the risk of seizure recurrence or SE after the first seizure is likely to be high in patients with acute focal cerebral lesions and diffuse CNS infections like meningoencephalitis and encephalitis. Of the patients who had seizure recurrence or developed $\mathrm{SE}$, in $69 \%$ the pathology was infection-related and the other commonality was cortical gray matter involvement. Probably this group of patients, particularly patients with CNS infections, with high risk of seizure recurrence may need AED prophylaxis, at least for the period of resolution or stabilization of acute CNS insult. This concept is best illustrated by the seizure disorder associated with SCG. A growing body of clinical observation supports the concept that the seizure disorder associated with SCG requires AED treatment for the period of resolution of $\mathrm{CT}$ lesion. ${ }^{[25]}$

When considering the results of this study the limitations of the study must be recognized. This is a highly selected population and the findings may not be generalizable. In developing countries CNS infections like Japanese encephalitis, tuberculous meningitis, bacterial meningitis and NCC are endemic and are frequent risk factors for new-onset acute symptomatic seizures. There is a need to study a large population of patients with these pathologies for the risk of recurrence of seizures as it may have therapeutic implications, possible AED prophylaxis.

\section{References}

1. Guidelines for epidemiologic studies on epilepsy. Commission on Epidemiology and Prognosis, International League Against Epilepsy. Epilepsia 1993;34:592-6.

2. Hauser WA, Annegers JF. Epidemiology of acute symptomatic seizures. In: Engle J Jr, Pedley TA, editors. Epilepsy: A comprehensive textbook. Vol 1. Lippincott-Raen: Philadelphia; 1998. p. 87-92

3. Bleck TP, Smith MC, Pierre-Louis SJ, Jares JJ, Murray J, Hansen CA. Neurolgic complications of critical medical illness. Crit Care Med 1993;21:98-103.

4. Wijdicks EF, Sharbrough FW. New-onset seizure in critically ill patients. Neurology 1993;43:1042-4.

5. Varelas PN, Spanaki M. Management of seizures in the critically ill. Neurologist 2006;12:127-39.

6. Varelas PN, Mirski MA. Seizures in the adult intensive care unit. J Neurosurg Anesthesiol 2001;13:163-75.

7. Varelas PN, Spanaki M. Management of seizures in the critically ill. Neurologist 2006;12:127-39

8. Jordan KG. Nonconvulsive seizures (NCS) and nonconvulsive statue epilepticus (NCSE) detected by continuous monitoring in the Neuro-ICU (NICU-CEEG). Neurology 1992;42:180.

9. Varelas PN, Haceln Bey L, Hether T, Terranova B, Spanaki MV. Emergent electroencephalogram in the intensive care unit indications and diagnostic yield. Clin EEG Neurosci 2004;35:173-80.

10. Towne AR, Waterhouse EJ, Boggs JG, Garnett LK, Brown AJ, Smith JR Jr, et al. Prevalence of nonconvulsive status epilepticus in comatose patients. Neurology 2000;54:340-5.

11. Proposal for revised clinical and electroencephalographic classification of epileptic seizures. From the Commission on Classification and Terminology of the International League Against Epilepsy. Epilepsia 1981;32:489-501.

12. Mitchell WG. Status epilepticus and acute repetitive seizures in children, adolescents and young adults: Etiology, outcome and treatment. Epilepsia 1996;37:S74-80.

13. Treiman DM, Meyers PD, Walton NY, Collins JF, Colling C, Rowan A.J, et al. A comparison of four treatments for generalized convulsive status epilepticus. N Eng J Med 1998;339:792-8.

14. Del Brutto OH, Rajashekhar V, Whit AC Jr, Tsang VC, Nash TE, Takayanagui OM, et al. Proposed diagnostic criteria for neurocysticercosis. Neurology 2001;57:177-83.

15. Rajashekhar V, Haran RP, Prakash GS, Chandy MJ. Diffeentiating solitary small cysticercus granuloma and tuberculoma in patients with epilepsy: Clinical and computerized tomographic cirteria. J Neurosurg 1993;78:402-7.

16. Gupta RK, Jeena A, Singh K, Sharma A, Puri V, Gupta M. Role of magnetic resonance $(\mathrm{MR})$ in the diagnosis and management of intracranial tuberculomas. Clin Radiol 1990;41:120-7.

17. Sander JW, Hart YM, Johnson AL, Shorvon SD. National General Practice Study of Epilepsy: Newly diagnosed epileptic seizures in a general population. Lancet 1990;336:1267-71.

18. Ettinger AB, Shinnar S. New-onset seizures in an elderly hospitalized population. Neurology 1993;43:489-92

19. Timmons S, Sweeney B, Hyland M, O'Mahony D, Twomey C. Newonset seizures in the elderly: Etiology and prognosis. Ir Med J 2002;95:47-9

20. Rajashekhar V, Chandy MJ. Clinical manifestation of solitary cysticercus granuloma. In: Rajashekhar V, Chandy M.J, editors. Solitary cysticercus granuloma. Orient Longman: Chennai; 2000. p. $29-39$

21. Annegers JF, Hauser WA, Lee JR, Rocca W. Incidence of acute symptomatic seizures in Rochester, Minnesota, 1935-1984. 
Epilepsia 1995;36:327-33.

22. Jallon P, Smadja D, Cabre P, Le Mab G, Bazin M. EPIMART: Prospective incidence study of epileptic seizures in newly referred patients in a French Carribean island (Martinique). Epilepsia $1999 ; 40: 1103-9$.

23. Huang CC, Chang YC, Wang ST. Acute symptomatic seizure disorders in young children - a population study in southern Taiwan. Epilepsia 1998;39:960-4.

24. Murthy JM, Yangala R. Acute symptomatic seizures - Incidence and etiological spectrum: A hospital-based study from south India.
Seizure 1999;8:162-5.

25. Murthy JM. Acute symptomatic seizures: Clinical and etiological spectrum in developing countries. In: Murthy JM, Senanayake N, editors. Epilepsy in tropics. Landes Bioscience: Georgetown; 2006. p. $133-43$.

Accepted on 18-01-2007

Source of Support: Nil, Conflict of Interest: None declared.

\section{Author Help: Online Submission of the Manuscripts}

Articles can be submitted online from http://www.journalonweb.com. For online submission articles should be prepared in two files (first page file and article file). Images should be submitted separately.

1) First Page File:

Prepare the title page, covering letter, acknowledgement, etc., using a word processor program. All information which can reveal your identity should be here. Use text/rtf/doc/pdf files. Do not zip the files.

2) Article file:

The main text of the article, beginning from Abstract till References (including tables) should be in this file. Do not include any information (such as acknowledgement, your names in page headers, etc.) in this file. Use text/rtf/doc/pdf files. Do not zip the files. Limit the file size to $400 \mathrm{~kb}$. Do not incorporate images in the file. If file size is large, graphs can be submitted as images separately without incorporating them in the article file to reduce the size of the file.

3) Images:

Submit good quality colour images. Each image should be less than $\mathbf{4 0 0} \mathbf{~ k b}$ in size. Size of the image can be reduced by decreasing the actual height and width of the images (keep up to about 3 inches) or by reducing the quality of image. All image formats (jpeg, tiff, gif, bmp, png, eps, etc.) are acceptable; jpeg is most suitable. The image quality should be good enough to judge the scientific value of the image.

Always retain a good quality, high resolution image for print purpose. This high resolution image should be sent to the editorial office at the time of sending a revised article.

4) Legends:

Legends for the figures/images should be included at the end of the article file. 